\title{
Modeling and Optimizing the Water Intake Side of Absorption Refrigeration System Based on Equivalent Thermodynamic Coefficient
}

\author{
Zhang Wei ${ }^{1,2, *}$ Lu Jun ${ }^{1}$, Shan Honghao ${ }^{1}$, Fu Daoyou ${ }^{3}$ and Huang Feng ${ }^{4}$ \\ ${ }^{1}$ College of Urban Construction and Environmental Engineering, Chongqing University, Chongqing 400030, China \\ ${ }^{2}$ School of Urban Construction Engineering, Chongqing Technology and Business Institute, Chongqing 401520, China \\ ${ }^{3}$ Chongqing Sino-French Energy Services Co., Ltd., Chongqing 400020, China \\ ${ }^{4}$ Laboratoire PHASE, Universite Toulouse III-Paul Sabatier, Toulouse 31062, France
}

Received 7 August 2018; Accepted 25 November 2018

\begin{abstract}
Simulation is an important way of studying the performance of absorption refrigeration systems. However, considering numerous influencing factors, existing studies mainly focus on a single device of the system and less on the coupling relationship between devices. To integrate and optimize the water intake side of the absorption chiller and improve the energy efficiency of the system, the study selected the integration of the absorption chiller, the cooling water supply and the return, and river water intake system as the research object and the absorption refrigeration system of Chongqing Danzishi CBD Energy Station as an example. A novel method for constructing the river water temperature prediction model was proposed. Then, the mathematical model of the absorption chiller and the water intake side of the transmission and distribution system was established via the data fitting method, and the accuracy was verified. Finally, the equivalent thermodynamic coefficient model was created and used to optimize the flow and temperature difference between the supply and return cooling water under different inlet temperatures of the cooling water and load rates of the absorption chiller. Results show that, (1) The cooling water inlet temperature has minimal effect on the optimal temperature difference between the supply and return water, and the load rate of the absorption chiller has a great influence. (2) When the absorption chiller operates at full load, the optimum temperature difference between the supply and return cooling water is $10{ }^{\circ} \mathrm{C}$, the optimum water intake flow is $87.80 \%$ of the rated flow, and the thermodynamic coefficient of the system can be increased by $14.40 \%$ after integration and optimization. The study shows that the energy efficiency of the water intake side of the absorption refrigeration system can be improved by creating a model on the basis of the equivalent thermodynamic coefficient and by applying it to the optimization. This method is fast, simple, and effective. To a certain extent, this study provides technical support for the further improvement of the energy efficiency of absorption refrigeration systems.
\end{abstract}

Keywords: Absorption refrigeration system, Water intake side, Modeling and optimizing, Equivalent thermodynamic coefficient

\section{Introduction}

As the main form of the second-generation energy system, distributed energy system (DES) has become an important trend of energy development. The development of heatdriven refrigeration technology promotes the high-efficiency distributed combined cooling heating and power (CCHP) technology [1]. The driving heat source of DES can be the waste heat of flue gas in the power process or low-grade heat, such as steam or hot water, which not only saves electricity but also reduces primary energy consumption, improves energy efficiency, and reduces greenhouse gas emissions. Among them, lithium bromide absorption chiller is a commonly used heat-driven refrigeration technology. To grasp the operation performance of the refrigeration system, the performance model of the system must be constructed, and the performance of the system must be optimized. However, the simulation of a refrigeration system often requires several parameters of the equipment and the influencing factors. However, the detailed parameters and

*E-mail address: zhangwei923@163.com

ISSN: $1791-2377$ @ 2018 Eastern Macedonia and Thrace Institute of Technology. All rights reserved. doi:10.25103/jestr.116.16 test results related to the equipment components are often regarded as technical secrets by manufacturers such that the available technical information is mostly insufficient [2-3]. Therefore, the equipment components are difficult to simulate and model in detail in accordance with the data provided by the manufacturer. Consequently, simulating the unit and system through a small amount of available parameter data to reflect the operation status of the unit and system accurately has become an urgent problem to be solved in the operation optimization of the absorption refrigeration system.

Numerous scholars have attempted to solve the problem from the virtual simulation and data fitting aspects. However, the simulation of the absorption refrigeration system is mostly aimed at the entire system [4-6] or the core unit of the system [7-8]. In the simulation of the entire absorption refrigeration system, the limited operating characteristics of the entire system are used to infer the operating characteristic of the unit of full operating conditions to perform backward inference of grey box theory modeling. Grey box theory does not study the transmission, conversion, and flowing process of energy and mass between the system components in detail but fully utilizes the relationship between the datas which input and output the system, and 
derives the system operation law. However, DES is a complex system involving several types of equipment, such as the cold and heat source systems of the internal combustion engine + lithium bromide absorption chiller. This method includes a water intake pump, cooling water pump, absorption chiller, internal combustion engine generator, air conditioning water pump, and terminal equipment. Therefore, the operation law of the internal components is difficult to reflect using the grey box model of the entire system, and difficulties are encountered in exploring its energy-saving potential. The simulation of the core units of the system has matured, and the optimization of the core units and air conditioning water transmission and distribution system has sufficient theoretical support. However, studies on the optimization of the water intake side of the absorption refrigeration system are few, especially those of river water as cooling water.

A coupling relationship exists among the energy consumption of the absorption refrigeration units, supply and return cooling water system, and river water intake system. Thus, selecting the "water intake side," which consists of these three parts, as the research object and studying its optimal operation strategy from a holistic perspective can produce intuitive and convincing optimization results. In this study, the mathematical model was established by the data fitting method, and the water flow and temperature difference between the supply and return cooling water were optimized when the temperature of the river water changes to determine the best operation strategy of the water intake side. Then, the energy-saving potential of the absorption refrigeration system was explored from the water intake side.

\section{State of the art}

Given the complexity of the distributed CCHP system and the coupling effect of various factors on the system, numerous studies have been conducted on the simulation and optimization of the absorption refrigeration system. The mathematical or physical model is generally believed to be capable of reflecting the actual performance of the absorption refrigeration system and to have an irreplaceable role in system optimization research. However, numerous factors affect system performance, including the temperature and flow of the cooling water, the temperature difference between the supply and return water, the operation characteristics of the absorption chiller, the gas consumption of internal combustion engines, the temperature and flow of exhaust gas, the temperature and flow of cylinder liner water and the air-conditioning water flow. Thus, considering all factors when modeling the absorption refrigeration unit and system is difficult.

At present, the static lumped parameter model is common in system or unit simulation. This model regards the entire system as a "grey box" and only considers the changes of system parameters at the inlet and outlet. This method is widely used to simulate absorption refrigeration systems. G. Xu et al. [4] analyzed the effects of heat recovery and solution recycling rates on the performance of the refrigeration system. Khalid [7] established the steadystate simulation model of a single-effect lithium bromide refrigerator on the basis of the conservation of energy and mass. J. Sun et al. [8] designed a mathematical model of a single-effect lithium bromide heat pump, considering the following four factors: cross-flow heat exchanger, 2D temperature and concentration distribution, local heat and mass transfer coefficient, and lithium bromide solution crystallization. In addition, numerous scholars [9-11] have modeled and simulated the thermodynamic performance of the dual-effect lithium bromide absorption chiller or heat pump and mainly studied the influences of the absorber, condenser, and generator temperatures on the performance of the refrigeration cycle. Scholars have performed simulations on the performance of the absorption refrigeration units in view of the external factors of the system. Jianjiao Zheng [1] showed that the inlet temperature of the cooling water has a considerable effect on refrigerator performance. The decrease in inlet temperature of the cooling water is beneficial to the efficient operation of refrigerators, but attention should be paid to the crystallization of the lithium bromide solution when the temperature is substantially low. In addition, scholars have paid attention to the relationship between the absorption refrigeration unit and gas engine and considered the influences of exhaust gas temperature and flow on the performance of the refrigeration unit. Sergio Arosio [5] linearly regarded the main equipment, such as the gas engine, as a black box and proposed an analysis model to analyze the effect of fiscal and taxation policies on the CCHP system performance. Sun Yalin [6] established a steady-state mathematical model of the dual-effect lithium bromide refrigeration system on the basis of the conservation of energy and mass. Sun Yalin analyzed the influence of parameters, such as the inlet temperatures and flows of the heat source water and cooling water and the outlet temperature and flow of the chilled water, on system performance. Sun Yalin also considered that the refrigeration capacity and coefficient of the system are directly proportional to the inlet temperature of the heat source water, especially the refrigeration capacity of the system that increases linearly. The influence of the heat source water flow on the refrigeration coefficient and capacity of the system is similar. C.W. Park et al. [12] conducted a thermodynamic performance simulation analysis of a direct-fired refrigeration unit. They found that the inlet temperature of the cooling water has a stronger effect on the performance of the refrigeration unit than the flow of the cooling water. A. A. Manzela et al. [13] performed an experimental study of an ammoniawater absorption chiller, with the exhaust gas of an internal combustion engine as the heat source. They analyzed the availability of exhaust gas and the effect of the absorption chiller on the performance of the internal combustion engine, exhaust gas emission, and system economy. Jianjiao Zheng [14] analyzed the thermodynamics of each heat exchange component of the refrigeration unit and established a model. The cycle of the refrigeration unit was simulated using thermophysical parameters, such as lithium bromide and exhaust gas, and the accuracy of the model was verified. In this type of research, many believe that the temperature and flow of the cooling water have a great influence on the performance of absorption units. In addition, numerous studies [15-19] have shown that the thermodynamic coefficient of the absorption refrigeration unit decreases linearly with the increase in cooling water inlet temperature. Studies [6], [20-21] have indicated that the refrigeration capacity and coefficient of performance $(C O P)$ of the absorption refrigeration unit increase with the cooling water flow under rated conditions. Other studies [22-27] have highlighted that the design principle of the "large temperature difference and small water flow" is 
Zhang Wei, Lu Jun, Shan Honghao, Fu Daoyou and Huang Feng/

Journal of Engineering Science and Technology Review 11 (6) (2018) 125 - 137

beneficial to the energy efficiency improvement of the system.

Simulation can comprehensively and accurately reflect the operation characteristics of the system or unit. However, in engineering practice, the required internal parameters are difficult to obtain accurately and completely for the simulation of specific units, and the existing simulation results do not have wide applicability in different types of units. Given the huge amount of simulation calculation is inconvenient in engineering application. The absorption unit is commonly isolated from the system and studied separately. The influence of the flow and temperature differences between the supply and return cooling water on the absorption refrigeration unit is contrary to their influence on the water intake pump. However, existing research fails to integrate the two. Few studies exist on the coupling of the intake water flow with the cooling water temperature and on the temperature difference between the supply and return water of the refrigeration unit. Moreover, studies on the simulation and optimization of the water intake side of the absorption refrigeration system, with river water as the cooling water, are limited.

Thus, this work used the "water intake side" of the DES integrated with absorption units, a supply and return cooling water system, and a river water intake system as the research object. To develop the performance model of the absorption refrigeration unit, data fitting was used as the modeling method for engineering application. For the external influencing factors of the unit, the temperature, water flow, and temperature difference between the supply and return cooling water were selected as independent variables affecting the thermophysical coefficient of the unit. For the internal structure and refrigerant characteristics of the chiller, the thermophysical coefficient of the chiller was modified by the influence of load rate on chiller performance. In the optimization of the water intake side, the river water temperature prediction and equivalent thermodynamic coefficient models were established for the two sidedness and coupling of the influence of temperature and the temperature difference between the supply and return cooling water on the water intake pump and absorption refrigeration unit. Thus, with the equivalent thermodynamic coefficient as the optimization objective, the optimal temperature difference between the supply and return water and the flow of the water intake were studied under different inlet temperatures of the cooling water and load rates of the absorption unit to optimize the energy efficiency of the water intake side.

The remainder of this study is organized as follows: Section 3 presents the prediction model of river water temperature with air temperature as the independent variable and the construction method of the performance model of absorption refrigeration unit with inlet temperature, water flow, and unit load rate as independent variables, on the basis of engineering application considerations. Then, the equivalent thermodynamic coefficient model of the absorption refrigeration unit and system is established. Section 4 develops the corresponding model of the case project via data fitting method, in accordance with the model construction method in Section 3, and model accuracy is verified. Then, with the equivalent thermophysical coefficient as the evaluation index, the optimal temperature difference between supply and return water and the intake flow of cooling water are analyzed. Section 5 draws the conclusions.

\section{Methodology}

The water intake side pump system of the absorption chiller studied in this work is divided into two stages. The first stage pumps river water to the reservoir of the absorption refrigeration energy station, and the second stage pumps the river water (cooling water) in the reservoir into the absorption units. The energy efficiency of the water intake system is mainly affected by the amount of water intake and the pump performance. The amount of water intake is determined by the amount of water demanded by the absorption unit. The factors affecting the water demand of the absorption unit include flow, temperature, the temperature difference between the supply and return cooling water, and the load rate of the unit determined by the cooling load. Therefore, these factors should be selected as the key points in the study of the operation optimization of the water intake side. Fig. 1 shows the research methods and technical routes.

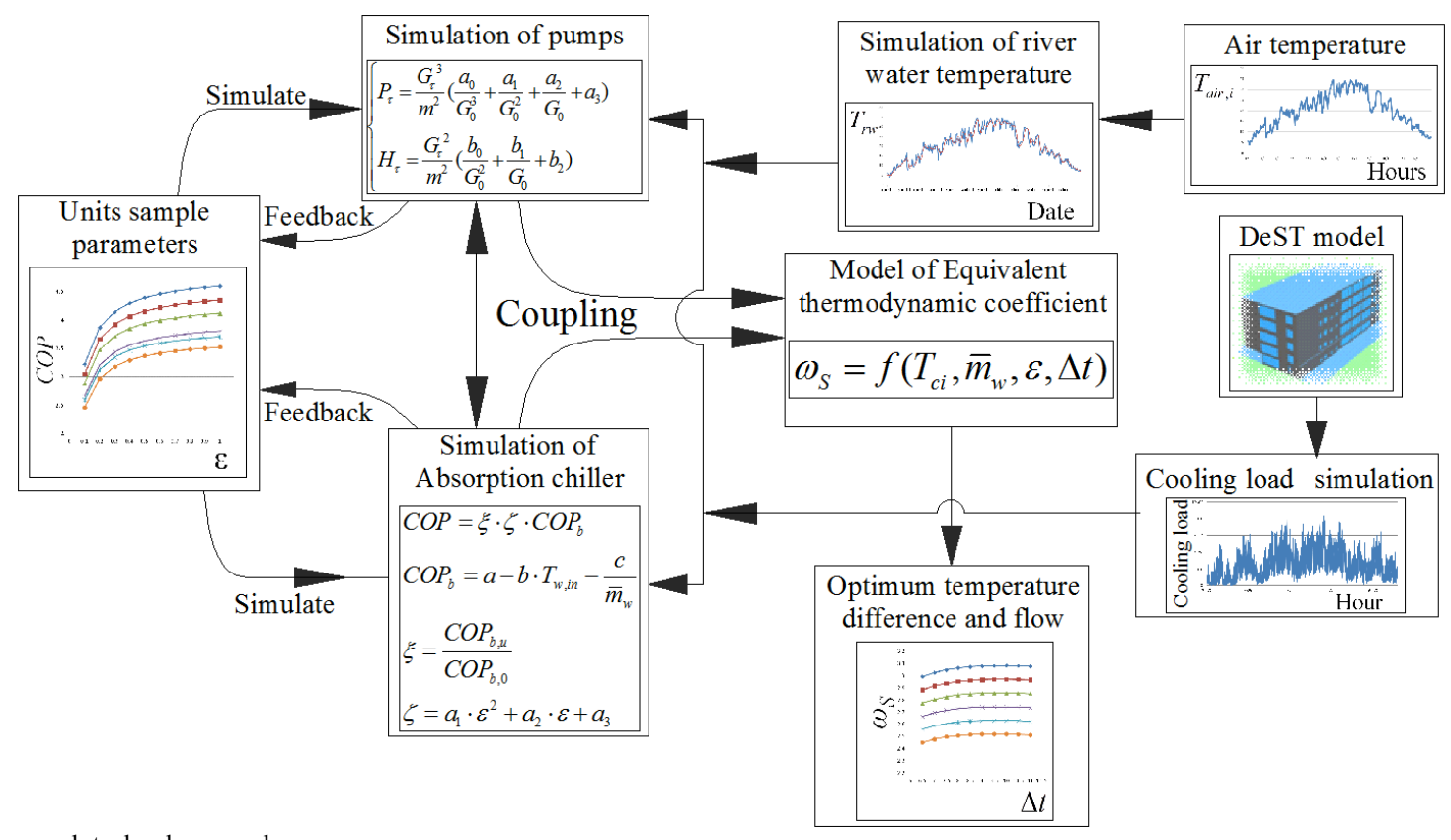

Fig. 1. Research technology roadmap 
First, the water temperature of Yangtze River where the case project is located is analyzed, and the water temperature prediction model is established to support the research and optimization of the water intake system of the absorption unit. Second, the performance model of the absorption refrigeration unit is constructed by selecting the flow, temperature, and temperature difference between the supply and return cooling water and the unit load rate as independent variables. Then, the model of the transmission and distribution system is established. The model mainly includes the performance model of pipelines and pumps. Considering the engineering application, the common performance models for the variable frequency and parallel operation of pumps are mainly constructed. Finally, the equivalent thermodynamic coefficient model of the absorption refrigeration system is established, and the optimal water flow and temperature difference between the supply and return water under different cooling water temperatures and building cooling loads are determined.

\subsection{Construction method of river water temperature prediction model}

Generally, solar radiation intensity, upstream water temperature, wind speed, local temperature, soil temperature, and so on have a great effect on river water temperature. The influence of these factors on river water temperature is relatively different in various regions. For example, the river water in the Chongqing section of Yangtze River has the characteristics of large discharge and fast flow speed. The highest total solar radiation in Chongqing is $487.0 \mathrm{MJ} / \mathrm{m}^{2}$, and the annual sunshine hours are low, belonging to the fifth and lowest categories of solar energy resources in China. The annual average wind speed is less than $1.5 \mathrm{~m} / \mathrm{s}$, and the wind resource is scarce. In addition, the annual change in shallow soil temperature in this area is not evident, and the change in shallow soil temperature is mainly affected by air temperature. The water temperature of Yangtze River in Chongqing is slightly affected by solar radiation and wind speed, and considerably affected by the air temperature and the temperature of the upstream inflow.

Temperature parameters are the easiest to obtain in all regions and the most comprehensive meteorological data to be recorded. Considering that the dependent variables should be easy to obtain, and the proposed water temperature model should be easy to solve, the first-order equation is applied to fit the relationship between air and water temperatures, and the basic model of river water temperature is obtained. In terms of the influence of upstream inflow water temperature, considering the influence of upstream air temperature, the basic model is modified to improve the accuracy. Fig. 2 presents the construction method of the river water temperature prediction model.

\subsubsection{Basic model}

Numerous scholars [28-30] have used the first-order equation of local daily temperature to predict the local river water temperature. The general form of this type of fitting equation is expressed in Equation (1):

$$
T_{r w, i}=a \cdot T_{a i r, i}+b
$$

where $T_{r w, i}$ represents the fitting value of the river water temperature on a certain day $\left({ }^{\circ} \mathrm{C}\right), a$ and $b$ denotes the fitting coefficients, and $T_{a i r, i}$ is the local temperature measured on a certain day $\left({ }^{\circ} \mathrm{C}\right)$.

This type of fitting equation can efficiently reflect the overall change law of water temperature, but unlike the measured river water temperature value whose change frequency is low and change range is small, the water temperature value obtained by fitting fluctuates frequently, and the change range is wide. The reason is that the air temperature changes more dramatically than the water temperature.

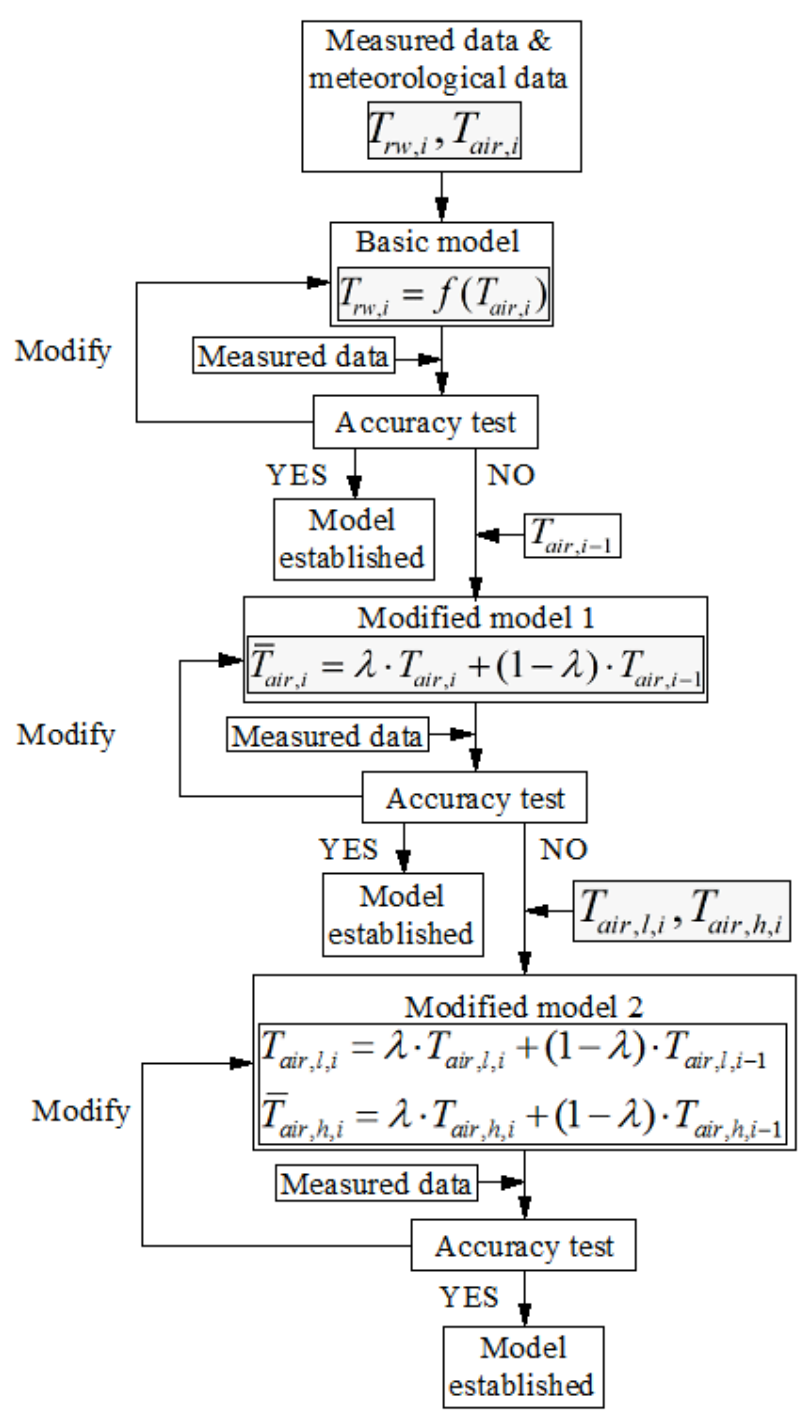

Fig. 2. Construction method of water temperature prediction model for Yangtze River

\subsubsection{Correcting by temperature data}

The direct way of improving the accuracy of the water temperature prediction model is to optimize the air temperature data selected. Let $T_{a i r, i-1}$ be the temperature of the previous day's upstream $\left({ }^{\circ} \mathrm{C}\right)$, and $\bar{T}_{a i r, i}$ be the weighted average value of $T_{a i r, i}$ and $T_{a i r, i-1}\left({ }^{\circ} \mathrm{C}\right)$; using $\bar{T}_{a i r, i}$ as the fitting parameter of the local river water temperature on that day has a clear theoretical importance. On the one hand, compared with $T_{a i r, i}$, the fluctuation frequency and amplitude of $\bar{T}_{a i r, i}$ are considerably reduced. On the other hand, $T_{a i r, i-1}$ is considered in $\bar{T}_{a i r, i}$; thus, $\bar{T}_{a i r, i}$ can indirectly reflect the influence of the upstream water temperature on the local 
water temperature. On the basis of the idea of this modeling method, Equation (1) is improved, and the water temperature prediction model is obtained, as shown in Equation (2):

$$
\left\{\begin{array}{l}
T_{r w, i}=a \cdot \bar{T}_{a i r, i}+b \\
\bar{T}_{a i r, i}=\lambda \cdot T_{a i r, i}+(1-\lambda) \cdot T_{a i r, i-1}
\end{array}\right.
$$

where $a$ and $b$ are the fitting coefficients and $\lambda$ indicates the weight coefficient of the influence of the local temperature measured on a certain day, $0<\lambda<1$.

\subsubsection{Correcting by sections}

However, document [21] indicates that false correlation of related data point cluster easily occurs, when the river water temperature is fitted and regressed in accordance with the air temperature data of the entire year. The main reason is the considerable difference between the river water temperatures in winter and summer. To avoid the false correlation of data point cluster, this study divides the entire year into two sections in accordance with the relationship between the river water and air temperatures. When most of the river water temperature is higher than the air temperature, it is regarded as a low-temperature section; otherwise, it is a high-temperature section. On the basis of Equation (2), the fitting model of river water temperature is established by two sections, as shown in Equation (3):

$$
\left\{\begin{array}{l}
T_{r w, l, i}=a \cdot \bar{T}_{\text {air }, l, i}+b \\
T_{r w, h, i}=c \cdot \bar{T}_{a i r, h, i}+d \\
\bar{T}_{a i r, l, i}=\lambda \cdot T_{a i r, l, i}+(1-\lambda) \cdot T_{a i r, l, i-1} \\
\bar{T}_{a i r, h, i}=\lambda \cdot T_{\text {air }, h, i}+(1-\lambda) \cdot T_{a i r, h, i-1}
\end{array}\right.
$$

where $T_{r w, l i}$ is the fitting value of a day's water temperature in the low-temperature section $\left({ }^{\circ} \mathrm{C}\right) ; T_{r w, h i}$ denotes the fitting value of a day's water temperature in the high-temperature section $\left({ }^{\circ} \mathrm{C}\right) ; a, b, c$, and $d$ represent the fitting coefficients; and $\bar{T}_{a i r, l, i}$ and $\bar{T}_{a i r, h, i}$ refer to the weighted average values of the temperature in the low- and high-temperature sections, respectively $\left({ }^{\circ} \mathrm{C}\right)$.

In this study, the river water temperature model established by Equation (3) is used to predict the water intake temperature of the absorption refrigeration system and optimize its operation.

\subsection{Construction method of the performance model of absorption refrigeration unit}

Numerous factors affect the performance of absorption refrigeration units: cooling water inlet temperature, cooling water flow, chilled water outlet temperature, chilled water flow, flue gas flow and temperature, hot water flow and temperature, and unit load rate. This study aims to simulate the performance of the water intake side of the absorption refrigeration unit. When modeling, the temperature and flow of the chilled water from the user side are constant, and the temperature and flow of flue gas and hot water are also constant. Then, the influence of cooling water temperature and flow on the performance of the absorption refrigeration unit is analyzed, and the model of the unit performance of cooling water inlet temperature and flow is established.

\subsubsection{Basic performance model of refrigeration unit}

Fig. 3 shows the modeling method of the absorption chiller.

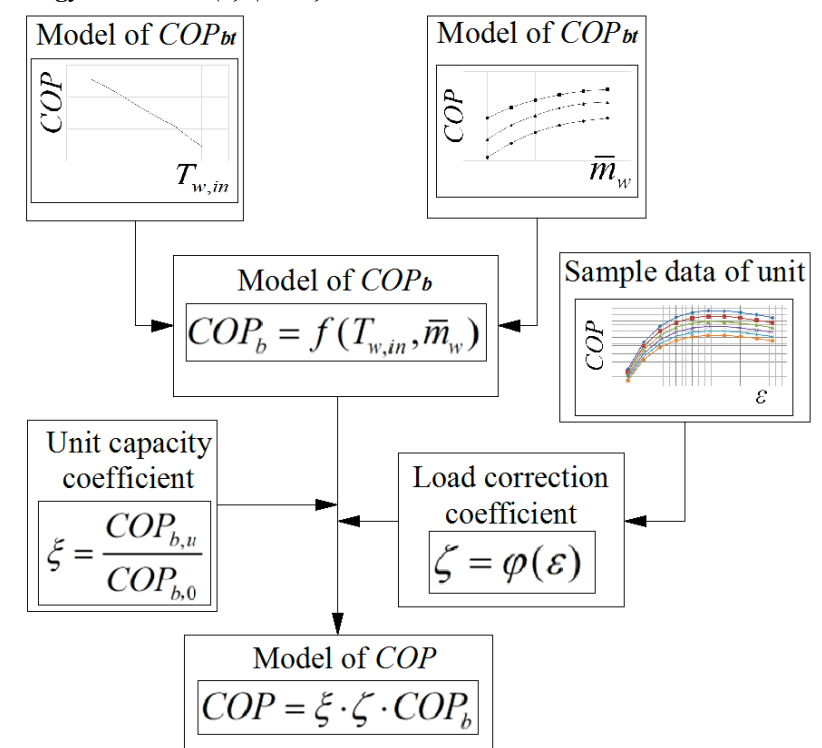

Fig. 3. Modeling method of absorption refrigerator

When studying the influence of the cooling water inlet temperature on the unit performance, the main method is to change the inlet temperature of the cooling water under the condition that the other operating parameters of the unit remain unchanged and to investigate the changes in the refrigeration capacity and $C O P$ of the unit. Results show that the performance coefficient of the absorption refrigeration unit decreases with the increase in cooling water inlet temperature, and its descending law shows a linear trend. Literature [24] indicates that the refrigeration capacity and $C O P$ of the unit have an approximately linear functional relation with the inlet temperature of the cooling water. Therefore, the relationship between the COP and cooling water temperature of the absorption refrigeration unit is shown in Equation (4):

$C O P_{b t}=a-b \cdot T_{w, i n}$

where $C O P_{b t}$ is the $C O P$ of the absorption refrigeration unit with the change in cooling water inlet temperature, $T_{w, i n}$ indicates the cooling water inlet temperature of the unit $\left({ }^{\circ} \mathrm{C}\right)$, and $\mathrm{a}$ and $\mathrm{b}$ represent the fitting coefficients.

The change in cooling water flow is also an important factor that affects the performance of absorption refrigeration units. Numerous studies have shown that the performance coefficient of an absorption refrigeration unit increases with the cooling water flow, whereas other parameters remain unchanged. Literature [1] indicates that the relationship among refrigeration capacity, performance coefficient, and cooling water flow is expressed in Equation (5):

$C O P_{b f}=c-\frac{d}{\bar{m}_{w}}$

where $C O P_{b f}$ is the $C O P$ of the absorption refrigeration unit varying with the cooling water inlet temperature, $\bar{m}_{w}$ indicates the ratio of the actual cooling water flow to the designed cooling water flow, and $c$ and $d$ refer to the fitting coefficients.

On the basis of the previous analysis and considering the influence of the cooling water inlet temperature and flow on the performance coefficient of an absorption refrigeration unit, the relationship among $C O P_{b}$, cooling water inlet 
temperature, and cooling water flow can be obtained under the condition that other parameters are rated, as shown in Equation (6):

$$
C O P_{b}=a-b \cdot T_{w, i n}-\frac{c}{\bar{m}_{w}}
$$

\subsubsection{Modification of the basic model}

For the same type of units with different capacities, the larger the unit capacity, the greater the $C O P$ value under the same operating conditions. The capacity difference can be fitted by the sample data of the unit or adjusted by the coefficient. In addition, numerous studies show that the performance coefficient of the absorption refrigeration unit increases first and then decreases with the increase in unit load rate. A quadratic polynomial model can be used to modify the influence of the unit load rate on the unit performance coefficient. In this study, the capacity adjustment coefficient $(\xi)$ and load rate correction coefficient $(\zeta)$ are defined as Equations (7) and (8), respectively.

$\xi=\frac{C O P_{b, u}}{C O P_{b, 0}}$

$\zeta=a_{1} \cdot \varepsilon^{2}+a_{2} \cdot \varepsilon+a_{3}$

where $C O P_{b, u}$ is the $C O P$ of the target unit under rated operating conditions and $C O P_{b, 0}$ denotes the $C O P_{b}$ value in Equation (6) when the cooling water inlet temperature and flow are rated. $\varepsilon$ represents the load rate of the unit, and $a_{1}, a_{2}, a_{3}$ are the fitting coefficients.

In summary, the operational performance model of the absorption refrigeration unit is shown in Equation (9).

$$
C O P=\xi \cdot \zeta \cdot C O P
$$

The model considers the influences of cooling water temperature, cooling water flow, and unit load rate. It is concise in form and clear in meaning, requires relatively less data, has explicit functions, is easy to calculate, and has good applicability.

\subsection{Construction method of energy consumption model for transport and distribution system}

\subsubsection{Performance model of hydraulic pipeline}

The water intake system of the absorption refrigeration system using river water as cooling water is an open hydraulic pipeline. The pipeline characteristic is shown in Equation (10).

$$
\left\{\begin{array}{c}
H=\Delta H_{i}+S \cdot G^{2} \\
\Delta H_{i}=H_{0}-H_{i}
\end{array}\right.
$$

where $\Delta H_{i}$ is the daily water intake height difference (m), $S$ denotes the resistance coefficient of the pipeline system $\left(\mathrm{s}^{2} / \mathrm{m}^{5}\right), G$ represents the flow in the pipeline $\left(\mathrm{m}^{3} / \mathrm{h}\right), H_{0}$ indicates the elevation of the engine room (m), and $H_{i}$ is the daily water level of the river (m).

The hourly water intake flow of the water intake system $\left(G_{i}\right)$ can be obtained by Equation (11).

$$
G_{i}=3600 \cdot \frac{Q_{i}+Q_{u, i}}{c_{w} \cdot \Delta t_{i} \cdot \rho}
$$

where $Q_{i}$ is the hourly cooling load (kW), $Q_{u, i}$ refers to the heat consumption of the unit in the system $(\mathrm{kW}), c_{w}$ indicates the specific heat capacity of water $\left(\mathrm{kJ} /\left(\mathrm{kg} \cdot{ }^{\circ} \mathrm{C}\right)\right), \Delta t_{i}$ denotes the hourly heat transfer temperature difference of the river water $\left({ }^{\circ} \mathrm{C}\right)$, and $\rho$ represents the water density $\left(\mathrm{kg} / \mathrm{m}^{3}\right)$.

\subsubsection{Parallel operation performance model of frequency converter pumps}

On the basis of the mechanical characteristics and similarity law of the centrifugal pump, when the revolution speed of the pump varies within a certain range, the relationship between flow, head, and power is shown in Equation (12).

$\left\{\begin{array}{c}\frac{G_{2}}{G_{I}}=\frac{n_{2}}{n_{1}} \\ \frac{H_{2}}{H_{1}}=\left(\frac{n_{2}}{n_{1}}\right)^{2} \\ \frac{P_{2}}{P_{1}}=\left(\frac{n_{2}}{n_{1}}\right)^{3}\end{array}\right.$

where $G$ is the water flow of the pumps $\left(\mathrm{m}^{3} / \mathrm{h}\right), H$ represents the pump head $\left(\mathrm{mH}_{2} \mathrm{O}\right), P$ denotes the pump power $(\mathrm{kW})$, and $n$ indicates the revolution speed of the pumps ( $\mathrm{r} / \mathrm{min}$ ). In engineering application, the working condition is often adjusted by varying the number of opening intake pumps, and the same type of pump is often selected for parallel operation. When $m$ pumps of the same type are connected in parallel in the system, the parallel operation performance model of frequency converter pumps is expressed as Equation (13).

$\left\{\begin{array}{l}H=H_{i} \\ G=\sum_{i=1}^{m} G_{i}=m G_{i} \\ P=\sum_{i=1}^{m} P_{i}=m P_{i}\end{array}\right.$

where subscript $i$ denotes the n-th pump.

The characteristic curve of the pump can be obtained by the testing method or from the product technical performance manual and then fitted by the "least square procedure." The study on the pump characteristic curve has been mature for a long time. Generally, the third-order form of the power equation and the second-order form of the head equation have high accuracy. When the same type of frequency conversion pumps are running in parallel at rated speed, the transmission and distribution system performance model of $G-H$ and $G-P$ of the water intake side is shown in Equation (14).

$\left\{\begin{array}{l}P_{\tau}=\frac{G_{\tau}^{3}}{m^{2}}\left(\frac{a_{0}}{G_{0}^{3}}+\frac{a_{1}}{G_{0}^{2}}+\frac{a_{2}}{G_{0}}+a_{3}\right) \\ H_{\tau}=\frac{G_{\tau}^{2}}{m^{2}}\left(\frac{b_{0}}{G_{0}^{2}}+\frac{b_{1}}{G_{0}}+b_{2}\right)\end{array}\right.$ 
where subscript ${ }^{\tau}$ denotes the t-moment, $a_{n}$ and $b_{n}$ are the fitting coefficients, and $G_{0}$ indicates the rated water flow of the pump $\left(\mathrm{m}^{3} / \mathrm{h}\right)$.

3.4 Construction method of the energy efficiency evaluation model for the absorption refrigeration system

A coupling relationship exists between the energy consumptions of the absorption refrigeration unit and cooling water pump. On the one hand, relevant research shows that the design principle of "large temperature difference, small flow" can reduce the water intake. Equations (13)-(14) show that reducing the cooling water flow will considerably reduce the energy consumption of the transmission and distribution system. On the other hand, Equations (4)-(6) present that with the decrease in cooling water flow and the increase in temperature difference between the supply and return cooling water, the condensation and evaporation temperatures of the refrigerant will increase, and the $C O P$ of the absorption refrigeration unit will decrease, thereby leading to the increase in the energy consumption of the refrigeration unit at the same refrigeration capacity. Therefore, the temperature difference between the supply and return water on the intake side of the cooling water cannot be increased indefinitely. However, an optimal temperature difference exists between the supply and return water. In this part, the energy efficiency evaluation model of the absorption refrigeration system is established, which selects the temperature of the cooling water intake, the temperature difference between the supply and return water, and the unit load rate as independent variables.

The equivalent thermal coefficient is based on the second law of thermodynamics. From the energy quality perspective, energies of different qualities are converted into primary energy and then compared. Equivalent thermodynamic coefficient is defined as the $\mathrm{kJ}$ refrigeration capacity obtained by consuming $1 \mathrm{~kJ}$ of fuel heat energy. In this study, the equivalent thermodynamic coefficient of the refrigeration system is used as an evaluation index. Equivalent thermodynamic coefficient $(\omega)$ is defined as the amount of $\mathrm{kJ}$ refrigerating output obtained by consuming 1 $\mathrm{kJ}$ of energy. In this study, the equivalent thermodynamic coefficient is used as an evaluation index of the absorption refrigeration system.

3.4.1 Equivalent thermodynamic coefficient model of the absorption refrigeration unit

In the absorption refrigeration system, the absorption refrigeration units are generally directly connected to the gas turbines or internal combustion engines, and the refrigeration system uses the flue gas and cylinder liner water discharged from the gas-fired generators as the direct heat source. Fig. 4 shows the energy input-output relationship of an absorption refrigeration unit.

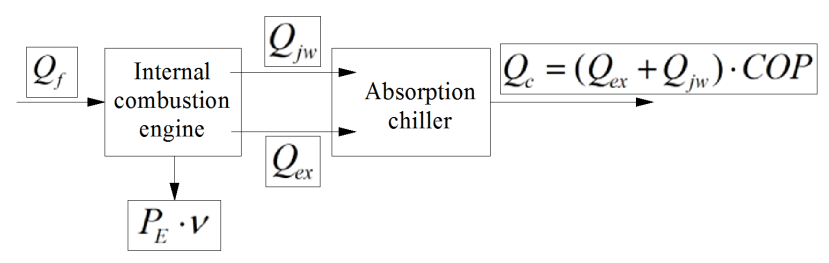

Fig. 4. Energy input-output relationship of absorption refrigeration

Coefficient $\mu$ is defined as the ratio of the amount of low-level heat energy recovered by the absorber for refrigeration to the amount of high-level heat energy contained in the fuel consumed. For absorption refrigeration units, the model of equivalent thermodynamic coefficient $\omega_{U}$ can be expressed as Equation (15).

$$
\left\{\begin{array}{c}
\omega_{U}=\mu \cdot C O P \\
\mu=\frac{Q_{e x}+Q_{j w}}{Q_{f}-P_{E} \cdot v} \\
Q_{e x}=m_{e x} \cdot c_{e x} \cdot\left(t_{e x}-t_{0}\right) \\
Q_{j w}=G_{j w} \cdot c_{j w} \cdot\left(t_{j w}-t_{0}\right)
\end{array}\right.
$$

where $Q_{e x}$ is the heat available from the exhaust of an internal combustion engine $(\mathrm{kJ}), Q_{j w}$ denotes the heat available from the cylinder liner water of the internal combustion engine $(\mathrm{kJ}), m_{e x}$ represents the exhaust volume of the internal combustion engine $(\mathrm{kg} / \mathrm{h}), c_{e x}$ indicates the specific heat of the exhaust gas of the internal combustion engine $(\mathrm{kJ} /(\mathrm{kg} \cdot \mathrm{K}))$, $t_{e x}$ refers to the exhaust temperature of the internal combustion engine $(\mathrm{K}), t_{0}$ is the ambient temperature $(\mathrm{K}), G_{j w}$ represents the water flow of the cylinder liner of the internal combustion engine $(\mathrm{kg} / \mathrm{h}), c_{j w}$ denotes the specific heat of the cylinder liner water of the internal combustion engine $(\mathrm{kJ} /(\mathrm{kg} \cdot \mathrm{K})), t_{j w}$ indicates the water drainage temperature of the cylinder liner of the internal combustion engine $(\mathrm{K}), Q_{f}$ stands for the amount of heat of the primary fuel $(\mathrm{K}), P_{E}$ is the power of the gas-fired generator $(\mathrm{kW})$, and $v$ represents the heat consumption rate of the gas-fired generators' power generation $(\mathrm{kJ} / \mathrm{kWh})$.

\subsubsection{Equivalent thermodynamic coefficient model of the refrigeration system}

The equivalent thermodynamic coefficient $\left(\omega_{S}\right)$ of the refrigeration system refers to how much cooling capacity $(\mathrm{kJ})$ can be output when the system consumes $1 \mathrm{~kJ}$ of heat of the primary fuel energy. The energy consumption of the absorption refrigeration system includes two parts. One part is the heat consumption of the system, including the heat contained in the exhaust gas and cylinder liner water of the gas-fired generators. The other part is the power consumption of the system. The model of $\omega_{S}$ can be expressed as Equation (16).

$$
\omega_{S}=Q_{c} \cdot\left(\frac{Q_{c}}{\omega_{U}}+\frac{Q_{e}}{\eta_{e} \cdot \eta_{n}}\right)^{-1}
$$

where $Q_{c}$ is the refrigeration capacity of the system $(\mathrm{kW})$, $Q_{e}$ indicates the power consumption of the system (kW), $\eta_{e}$ denotes the power generation efficiency of the gas-fired generators, and $\eta_{n}$ represents the efficiency of the power grid.

\section{Result Analysis and Discussion}

The Danzishi CBD Economic Zone in Chongqing, China, has a total floor area of $799,900 \mathrm{~m}^{2}$ and a plot ratio of 4.71 . It is located at the intersection of Yangtze and Jialing Rivers, leans back on Nanshan Mountain, and faces Yangtze River in the east, north, and west. The first phase of the project consists of two office buildings with a floor area of 130700 $\mathrm{m}^{2}$. The hourly cooling load of the first phase of the project is simulated dynamically by using the DeST energy 
consumption analysis software. The hourly cooling load is obtained, as shown in Fig. 5, considering the coefficients of the simultaneous use of all buildings.

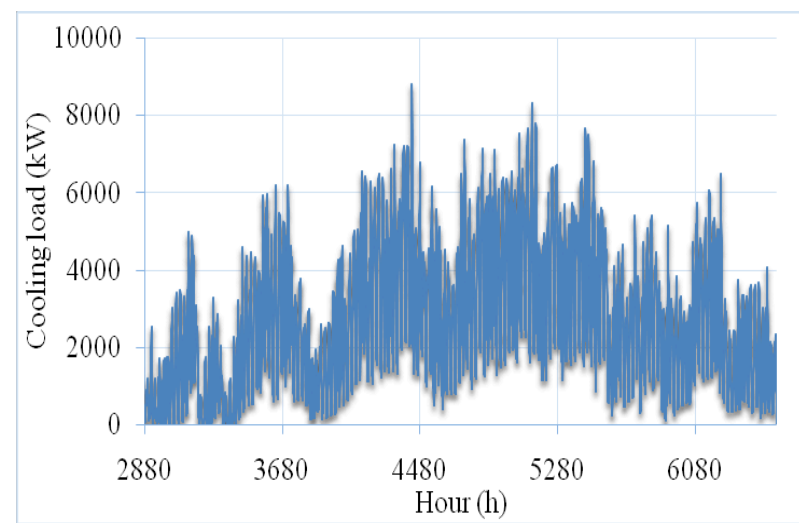

Fig. 5. Hourly distribution of air-conditioning load in buildings of the first phase

Results show that the maximum cooling load of the first phase of the project is $8785.27 \mathrm{~kW}$. The number of cooling load hours under $50 \%$ of the maximum cooling load accounts for $78.70 \%$ of the air-conditioning operation time in summer, and the time under $30 \%$ of the maximum cooling load accounts for $49.05 \%$ of the total time. The accumulative total cooling load is 9.737 million $\mathrm{kWh}$.

The energy station uses the combined energy system of natural gas CCHP and the river water source heat pump to provide regional energy for the project. In the first phase of the project, the equipment of the CCHP system is configured with two internal combustion generators with a generating capacity of $1063 \mathrm{~kW}$ and two flue gas and hot water-type absorption refrigeration units with a refrigeration capacity of $1021 \mathrm{~kW}$.

\subsection{Establishment of river water temperature model}

The river flow velocity in the Chongqing section of Yangtze River where the project is located is between $0.5 \mathrm{~m} / \mathrm{s}$ and 0.7 $\mathrm{m} / \mathrm{s}$, and on the previous day, the river water was located in Hechuan District, Chongqing. On the basis of Equation (3), the air temperature data of the Chongqing urban area and Hechuan area upstream are processed in sections and compared with the measured water temperature of Jialing River in the project location. The variation of water temperature with air temperature is obtained and shown in Figs. 6-7.

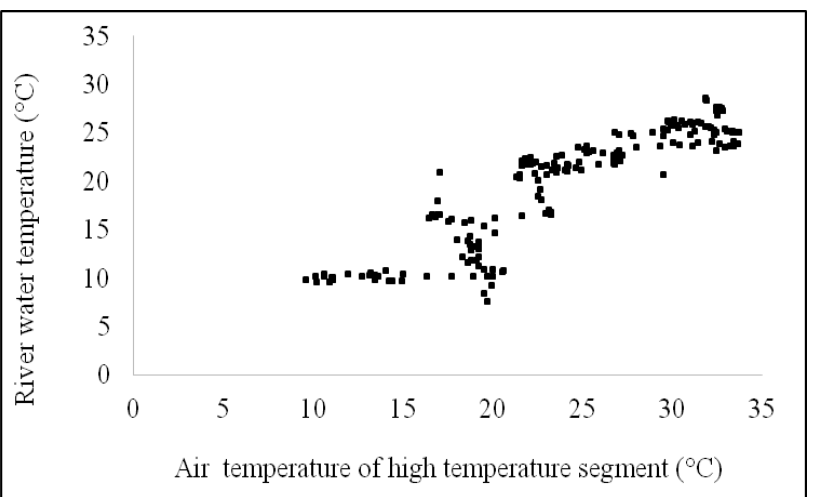

Fig. 6. Variation of river water temperature with air temperature in high-temperature sections

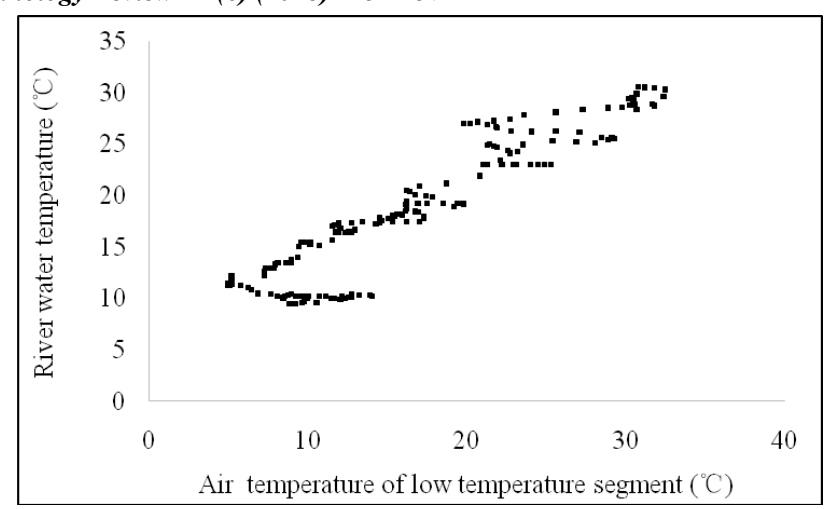

Fig. 7. Variation of river water temperature with air temperature in low-temperature sections

The river water temperature changes with the air temperature after the segmentation shows considerable linear correlation characteristics.

August 15 to February 15 is designated as the lowtemperature section, and February 16 to August 14 is designated as the high-temperature section. On the basis of Equation (3), the fitting model of the river water temperature is established. $\lambda$ is optimized to 0.4 , and the fitting Equation (17) is obtained.

$\left\{\begin{array}{l}T_{r w, l, i}=0.781 \cdot \bar{T}_{a i r, l, i}+5.581 \\ T_{r w, h, i}=0.811 \cdot \bar{T}_{a i r, h, i}+0.189\end{array}\right.$

The fitting correlation coefficients of the previous two formulas are 0.927 and 0.894 , respectively. In comparison with the fitting correlation coefficient of 0.715 obtained by Equation (1), the fitting correlation coefficients of the two formulas are remarkably improved, indicating that the river water temperature model described by Equation (17) can efficiently reflect the correlation between air and river water temperatures.

Fig. 8 shows the comparison between the fitted and measured water temperatures.

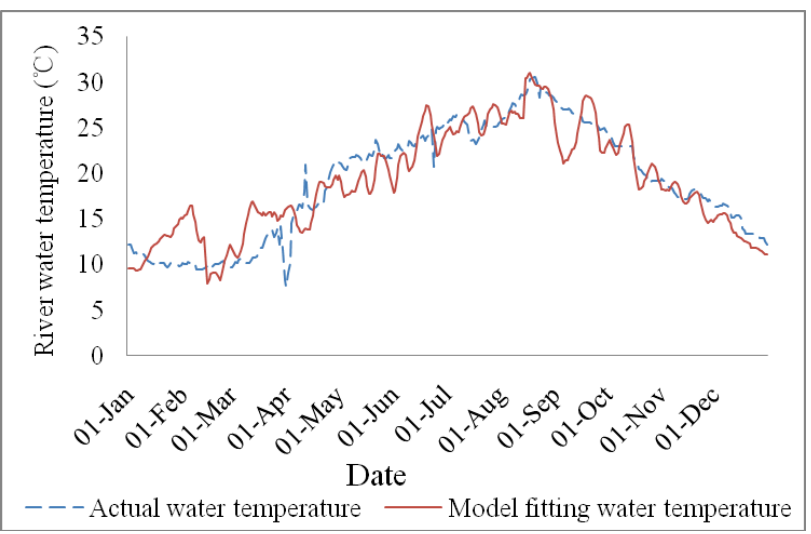

Fig. 8. Comparison chart between the simulated and measured water temperatures

\subsection{Establishment of the absorption refrigeration unit} model

In the case project, BZHE100XD flue gas and hot watertype lithium bromide absorption unit of BROAD company are selected as the absorption units. Table 1 presents the design performance parameters of the unit under refrigeration conditions. 
Zhang Wei, Lu Jun, Shan Honghao, Fu Daoyou and Huang Feng/

Journal of Engineering Science and Technology Review 11 (6) (2018) 125 - 137

Table 1. Refrigeration performance parameter of absorption unit

\begin{tabular}{|c|c|c|c|c|c|c|c|}
\hline $\begin{array}{l}\text { Absorption } \\
\text { chiller } \\
\text { model }\end{array}$ & $\begin{array}{l}\text { Rated } \\
\text { capacity } \\
(\mathbf{k W})\end{array}$ & $\begin{array}{l}\text { Flue gas emission } \\
(\mathrm{kg} / \mathrm{h})\end{array}$ & $\begin{array}{l}\text { Rated } \\
\text { exhaust gas } \\
\text { temperature } \\
\left({ }^{\circ} \mathrm{C}\right) \\
\end{array}$ & $\begin{array}{l}\text { Cooling water } \\
\text { flow }\left(\mathrm{m}^{3} / \mathrm{h}\right) \text {, } \\
\text { inlet and outlet } \\
\text { temperature }\left({ }^{\circ} \mathrm{C}\right)\end{array}$ & $\begin{array}{l}\text { Chilled water } \\
\text { flow }\left(\mathrm{m}^{3} / \mathrm{h}\right) \text {, } \\
\text { inlet and outlet } \\
\text { temperature }\left({ }^{\circ} \mathrm{C}\right)\end{array}$ & $\begin{array}{l}\text { Power } \\
\text { distribution } \\
(\mathbf{k W})\end{array}$ & $\begin{array}{l}\text { Rated } \\
\text { thermodynamic } \\
\text { coefficient }\end{array}$ \\
\hline BZHE100XD & 1163 & 6003 & 160 & $255,32 / 25$ & $143,7 / 14$ & 16.7 & 1.35 \\
\hline
\end{tabular}

The BZHE100XD absorption chiller is modeled by using the method of Equations (6)-(9), as shown in Equation (18).

$$
\left\{\begin{array}{l}
C O P_{b}=3.435-0.0188 T_{c i}-\frac{1.5210}{\bar{m}_{w}} \\
\zeta=1.2094 \varepsilon^{3}-2.9073 \varepsilon^{2}+2.2789 \varepsilon+0.4190
\end{array}\right.
$$

4.3 Establishment of the model for the water intake side transportation and distribution system

The water intake system of the case project adopts the twostage variable flow water intake system. Table 2 lists the parameters of the first- and second-grade water intake pumps.

Table 2. Parameters of river water intake pump

\begin{tabular}{l|l|l|l|l|l|l|l}
\hline $\begin{array}{l}\text { Pumps } \\
\text { identifier }\end{array}$ & $\begin{array}{l}\text { Water flow } \\
\text { (CMH) }\end{array}$ & $\begin{array}{l}\text { Pump head } \\
\text { (kPa) }\end{array}$ & $\begin{array}{l}\text { Power } \\
\text { consumption (kW) }\end{array}$ & $\begin{array}{l}\text { Speed } \\
\text { revolution } \\
\text { (rpm) }\end{array}$ & $\begin{array}{l}\text { Work } \\
\text { efficiency }\end{array}$ & Number \\
\hline RWPS-3/4 & 280 & 180 & 22 & 1450 & 0.78 & 2 \\
RWP-1-4 & 2750 & 370 & 260 & 740 & $\begin{array}{l}\text { Second-grade } \\
\text { intake pump } \\
\text { First-grade } \\
\text { intake pump } \\
\text { water }\end{array}$ \\
\hline
\end{tabular}

On the basis of the sample data provided by the manufacturer, the Origin software was used to fit the performance curve of the water intake pump. The energy consumption model of the $m$ water intake pumps under the frequency conversion operation was obtained as shown in Equation (19).

$\left\{\begin{array}{l}R W P S-3 / 4: P_{\tau}=\frac{G_{\tau}^{3}}{m^{2}} \cdot\left(\frac{22.7641}{0.0700^{3}}+\frac{-2.6827}{0.0700^{2}}+\frac{53.5855}{0.0700}-35.9766\right) \\ R W P-1 \sim 4: P_{\tau}=\frac{G_{\tau}^{3}}{m^{2}} \cdot\left(\frac{156.3164}{0.7639^{3}}+\frac{-18.1884}{0.7639^{2}}+\frac{358.2244}{0.7639}-240.8812\right)\end{array}\right.$

By adjusting the frequency converter to change the river water inflow, frequencies 50, 45, 40, 35, and $30 \mathrm{~Hz}$ were tested. Fig. 9 shows the pictures of the spot test.

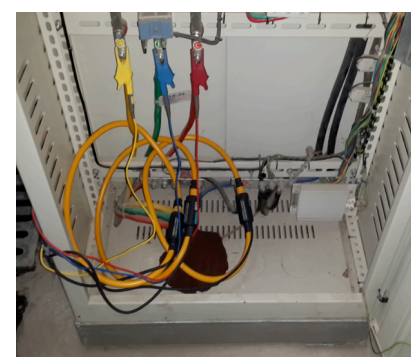

Fig. 9. Pictures of the spot test

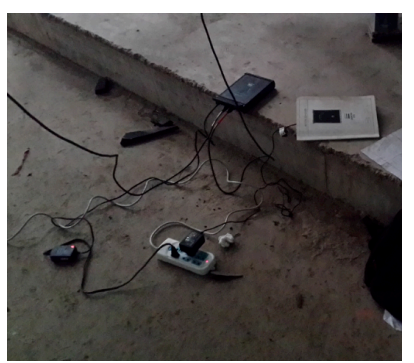

The test data and simulated energy consumption values of the first- and second-grade water intake pumps are plotted in the same coordinate system, as shown in Figs. 10-11, respectively.

Results show that the errors between the simulated energy consumption values of the first- and second-grade pumps and the field measured values are relatively small, ranging from $6 \%$ to $7 \%$ and $2 \%$ to $4 \%$, respectively. Hence, the energy consumption models of the first- and secondgrade water intake pumps have high accuracy.

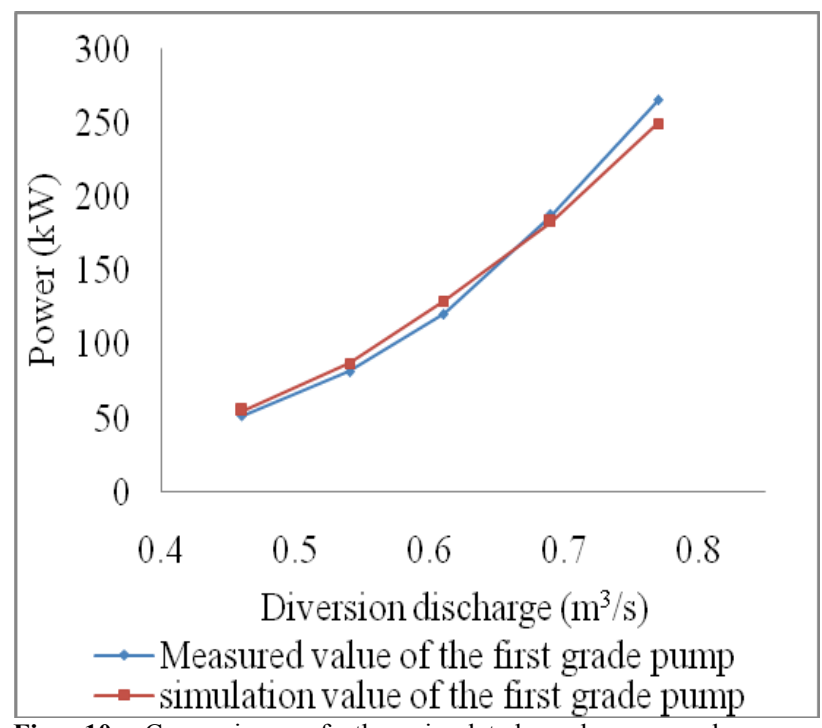

Fig. 10. Comparison of the simulated and measured energy consumption values of first-grade water intake pumps

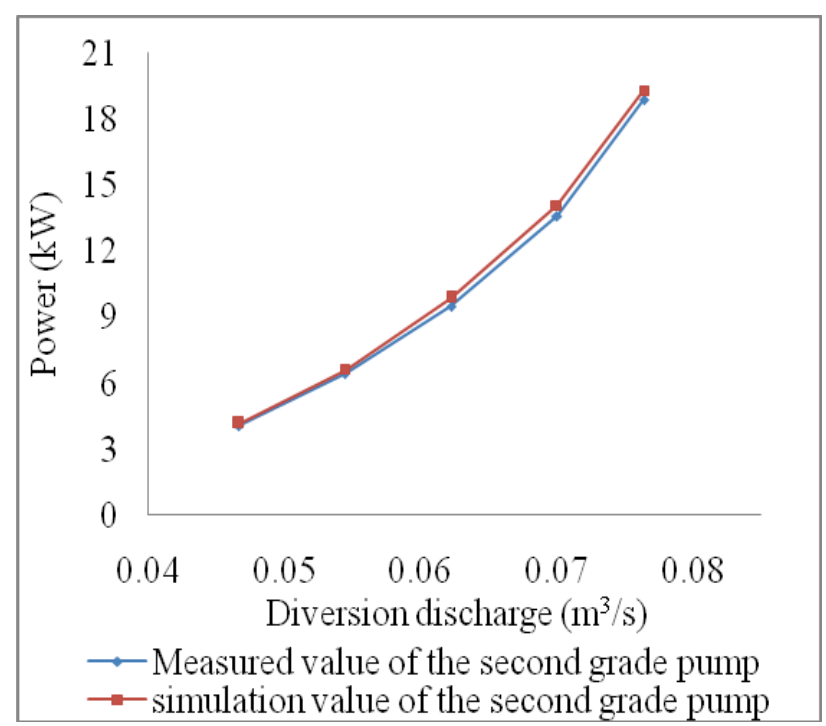

Fig. 11. Comparison of the simulated and measured energy consumption values of second-grade water intake pumps 
Zhang Wei, Lu Jun, Shan Honghao, Fu Daoyou and Huang Feng/

Journal of Engineering Science and Technology Review 11 (6) (2018) 125 - 137

4.4 Establishment of the equivalent thermodynamic coefficient model for absorption refrigeration system

Given that the first-grade pump is shared by all units in the entire project, the water withdrawal is considerably larger than that in the second-grade pump. The excessively lowload operation of the pump will damage the pump. However, even if the absorption chillers of the first-phase project are under full-load operation, the cooling water required cannot reach the lower limit of the frequency conversion range set by the first-grade pump. Therefore, this study does not consider the frequency conversion condition of the firstgrade water intake pumps, but only the energy consumption change caused by the frequency conversion operation of the second-grade water intake pumps directly connected to the absorption chillers.

On the basis of the actual performance parameters of the absorption chillers and pumps, the equivalent thermodynamic coefficient of the water intake side can be obtained by combining Equations (15)-(16) and (18)-(19), as shown in Equation (20).

$$
\omega_{S}=\left[\frac{1}{2.1098 \cdot C O P}+1.5901 \cdot \varepsilon^{2} \cdot\left(\frac{1+\frac{1}{C O P}}{\Delta t}\right)^{3}\right]^{-1}
$$

\subsection{Study on the operation optimization of water intake side}

Equation (20) shows that the equivalent thermodynamic coefficient of the water intake side is related to the load rate, the inlet temperature of cooling water, and the temperature difference between the supply and return cooling water $(\Delta t)$.

The optimal temperature difference of the supply and return cooling water under different conditions is studied with the system equivalent thermodynamic coefficient as the optimization objective. Figs. 12-13 present the results.

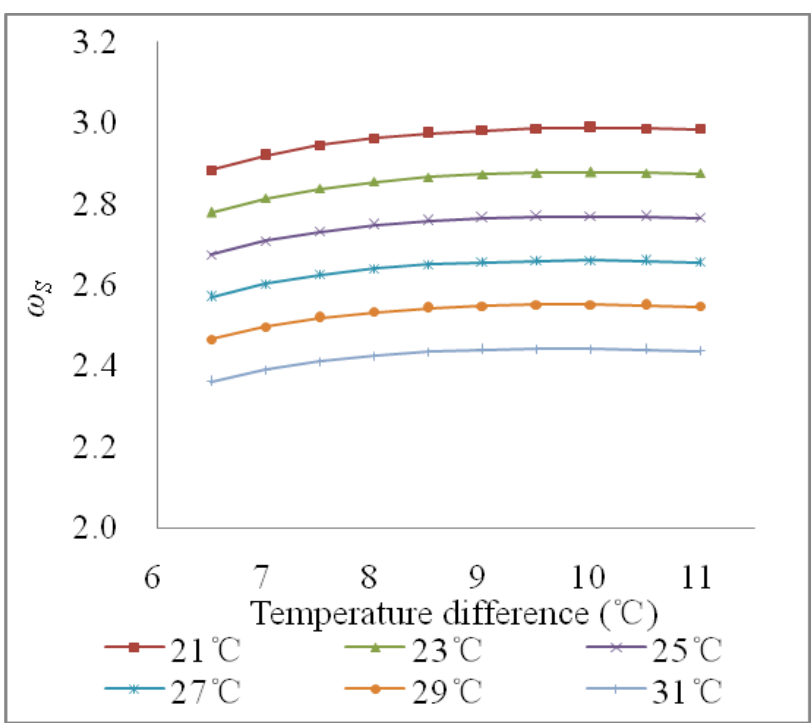

Fig. 12. Relationship between $\omega_{S}$ and $\Delta t$ of the cooling water under different $T_{w, i n}$ values

Fig. 12 shows that under the rated load rate, the equivalent thermodynamic coefficient of the system decreases with the increase in cooling water inlet temperature, which is mainly due to the decrease in the performance coefficient of the absorption chillers with the increase in cooling water inlet temperature. At the same cooling water temperature, the equivalent thermodynamic coefficient of the system increases gradually at first and then decreases after reaching the maximum with the increase in temperature difference between the inlet and outlet of the cooling water. This phenomenon occurs because with the increase in temperature difference between the inlet and outlet water, the performance coefficient of the chillers decreases, and the power consumption increases, whereas the power consumption of the cooling water pump decreases. Therefore, an optimum temperature difference exists in the intake water side, such that the equivalent thermodynamic coefficient of the intake water side can reach the optimum. Fig. 13 shows that the same relationship exists between the cooling water flow and equivalent thermodynamic coefficient.

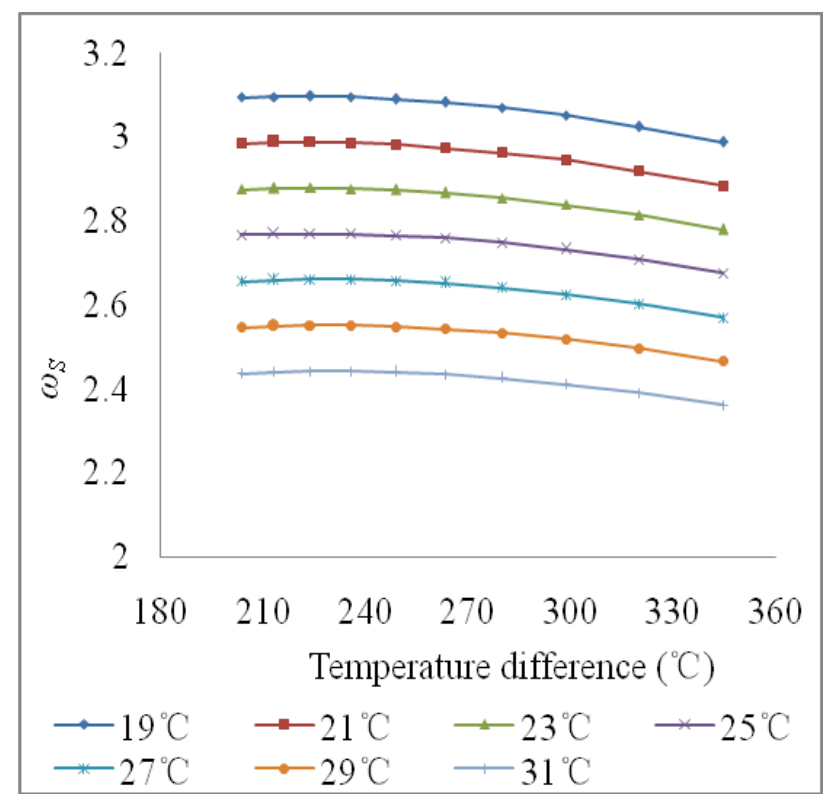

Fig. 13. Relationship between $\omega_{S}$ and flow of the cooling water under different $T_{w, i n}$ values

Besides temperature, flow, and the temperature difference between the supply and return cooling water, the load rate of absorption chillers is also an important factor that affects the energy efficiency of the intake water side. With the cooling water temperature as an example, the optimal temperature difference between the supply and return cooling water under partial load is studied. Under the partial load rate of chillers and with the changing of cooling water inlet temperature, Figures 14-17 show the relationship between $\omega_{S}$ and $\Delta t$.

Figs. 14-17 show the following: (1) Under different load rates, the change trend of the $\omega_{S}$ value of the water intake side with the temperature difference between the inlet and outlet of the cooling water is the same, that is, it increases first and then decreases. (2) With the decrease in load rate, the $\omega_{S}$ values of the system increases first and then decreases with the same cooling water temperature and temperature difference between the inlet and return water. (3) At the same load rate of the chillers, the optimal temperature difference between the supply and return cooling water corresponding to different cooling water inlet temperatures is the same. (4) Under different load rates, the optimal water flow and temperature difference between the supply and return cooling water are different. Table 3 shows the results. 


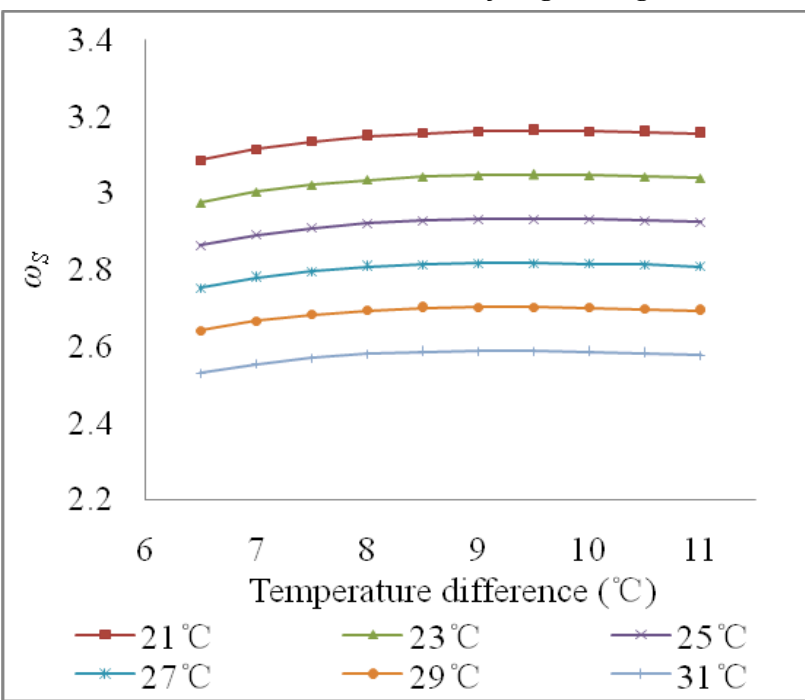

Fig. 14. Relationship between $\omega_{S}$ and $\Delta t$ under different $T_{w, i n}$ values when $\varepsilon=90 \%$

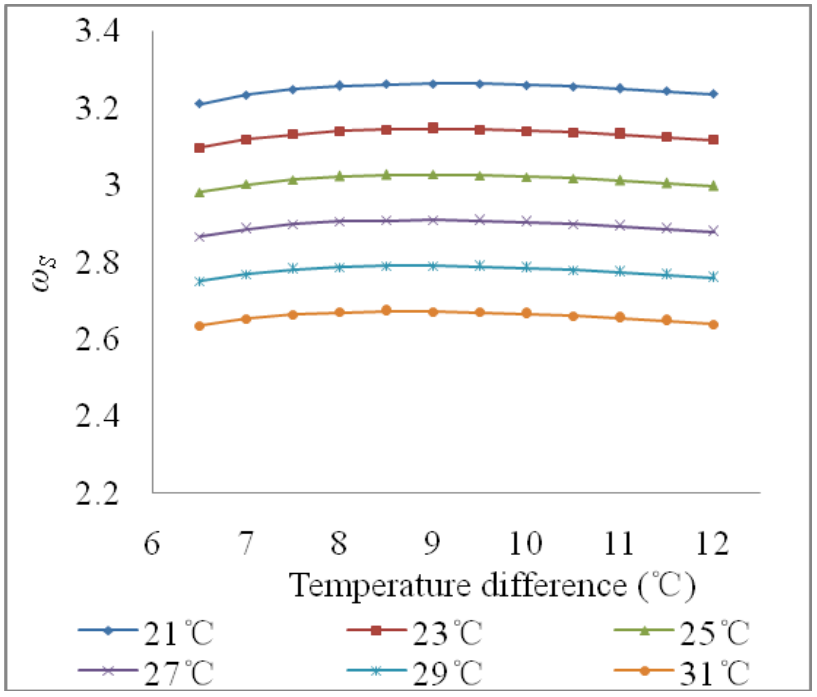

Fig. 15. Relationship between $\omega_{S}$ and $\Delta t$ under different $T_{w, i n}$ values when $\varepsilon=80 \%$

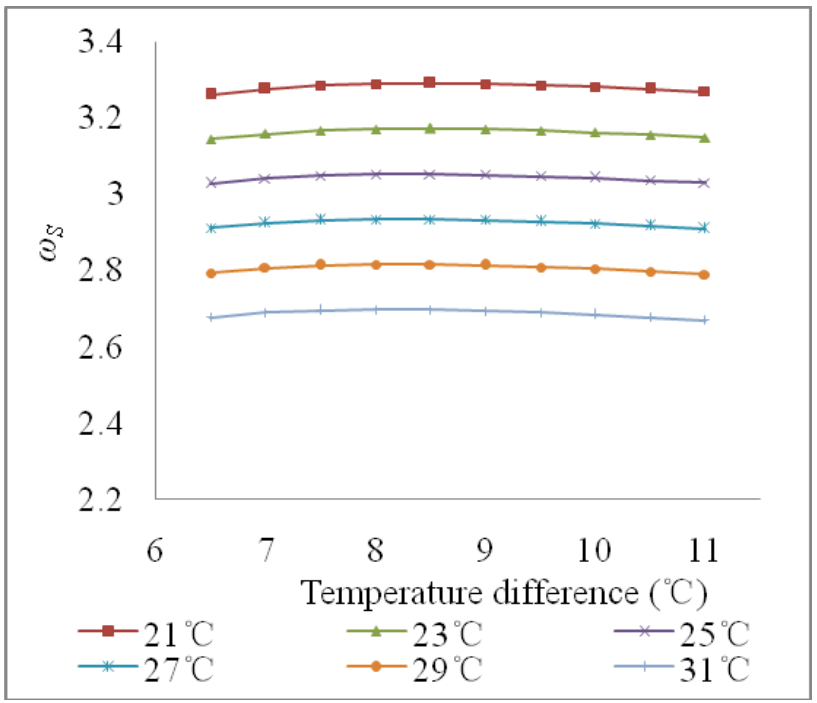

Fig. 16. Relationship between $\omega_{S}$ and $\Delta t$ under different $T_{w, i n}$ values when $\varepsilon=70 \%$

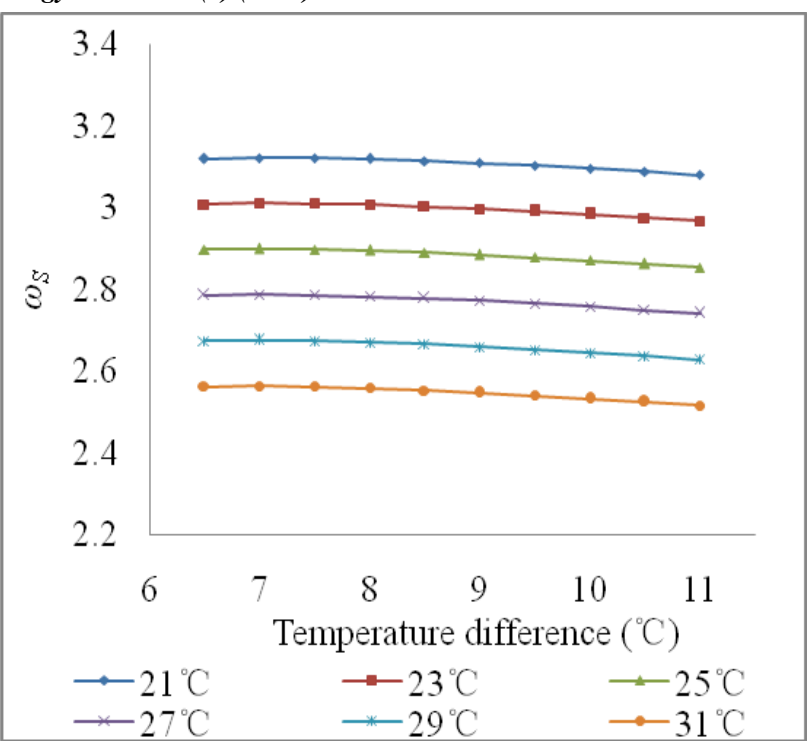

Fig. 17. Relationship between $\omega_{S}$ and $\Delta t$ under different $T_{w, i n}$ values when $\varepsilon=60 \%$

Table. 3. Optimal winter intake flow and temperature difference under various load rates

\begin{tabular}{l|l|l|l|l|l|l}
\hline Load rates & $\mathbf{1 0 0} \%$ & $\mathbf{9 0 \%}$ & $\mathbf{8 0 \%}$ & $\mathbf{7 0 \%}$ & $\mathbf{6 0 \%}$ & $\mathbf{5 0 \%}$ \\
\hline $\begin{array}{l}\text { Optimal } \\
\text { temperature } \\
\text { difference } \\
\left({ }^{\circ} \mathrm{C}\right)\end{array}$ & 10 & 9.5 & 9.0 & 8.5 & 8.0 & 7.0 \\
$\begin{array}{l}\text { Optimal } \\
\text { water } \\
\text { intake flow } \\
\left(\mathrm{m}^{3} / \mathrm{h}\right)\end{array}$ & 223.96 & 236.01 & 249.11 & 263.63 & 279.92 & 319.89 \\
\hline
\end{tabular}

Analysis results show that different cooling water inlet temperatures have minimal influence on the optimal temperature difference between the supply and return cooling water. At the same load rate, the optimal temperature difference between the supply and return cooling water is the same under different cooling water inlet temperatures. Different load rates have a considerable influence on the optimal temperature difference between the supply and return cooling water, and the optimal temperature difference decreases with the load rate. When the absorption chillers operate at full load, the optimal difference between the supply and return cooling water is $10^{\circ} \mathrm{C}$, and the optimal water intake flow is $223.96 \mathrm{~m}^{3} / \mathrm{h}$, which is $87.8 \%$ of the chillers' rated flow. At this time, $\omega_{S}$ is 2.769 , which is increased by $14.40 \%$ compared with that at the rated cooling water flow of $255 \mathrm{~m}^{3} / \mathrm{h}$ and the temperature difference between the supply and return cooling water of $7{ }^{\circ} \mathrm{C}$, exhibiting an evident optimization effect.

For a certain flow rate, in the increase of the temperature difference between the supply and return water, a critical point exists for $\omega_{S}$ to change from an increasing to decreasing trend. When $\omega_{S}$ reaches this critical point, the corresponding temperature difference between the supply and return water is the optimal operating temperature difference of the water intake side. Therefore, the design principle of "large temperature difference, small flow" is not infinitely applicable. Although considerable energy consumption is saved under the variable flow operation strategy, a small pump water flow does not always indicate high energy efficiency for the entire system. Similarly, a large temperature difference between the supply and return water does not always indicate high energy efficiency. 
Zhang Wei, Lu Jun, Shan Honghao, Fu Daoyou and Huang Feng/

Journal of Engineering Science and Technology Review 11 (6) (2018) 125 - 137

Therefore, the water intake side of the absorption refrigeration system must be optimized.

\section{Conclusions}

To model and optimize the water intake side of the absorption refrigeration system and avoid the unreasonable application of the design principle of "large temperature difference and small water flow" of the cooling water, the data fitting method was used to establish a river water temperature prediction model, an absorption chiller and water intake side transmission and distribution system model, and the equivalent thermodynamic coefficient model of the water intake side of the refrigeration system. These models were applied to the operation optimization of the water intake side of the Danzishi CBD energy station in Chongqing, China. The following conclusions were drawn:

(1) On the basis of the 1D model for temperature prediction, three corrections were made from the aspects of average temperature, the upstream incoming water temperature and high-/low-temperature section, and a new model for river water temperature prediction was established. The new model is simple in form, and the required parameters are easily obtained. The model was proven to be highly accurate and can be used for optimizing the water intake side of the absorption refrigeration system.

(2) By using the data fitting method, the off-design model of the absorption refrigeration unit, which selected the inlet temperature and flow of cooling water as independent variables and was modified by the capacity and load rate influence coefficients of the unit, was established. The model is concise in form and clear in meaning, requires relatively less data parameters, has explicit functions, and has strong applicability in engineering applications.

(3) An evaluation model based on the equivalent thermodynamic coefficient was created. The model was applied to investigate the optimal temperature difference and flow of the cooling water under different inlet temperatures and load rates of chillers. Results show that, for a certain water flow, in the increase of the temperature difference between the supply and return water, a critical point exists for the equivalent thermodynamic coefficient to change from an increasing to decreasing trend. The design principle of the cooling water with "large temperature difference and small flow" should be verified in engineering application.

In brief, the model of the absorption refrigeration system based on the equivalent thermodynamic coefficient constructed in this study can accurately reflect the actual operation state of the water intake side of the absorption refrigeration system. The forecasting model can accurately reflect the actual river water temperature of the section where the case project is located. The equivalent thermodynamic coefficient model based on the two models can determine the optimal temperature difference and water intake flow of the cooling water in the absorption refrigeration system, thereby providing convenient and accurate technical support for the operation and optimization of the water intake side and the optimization of the entire system.

However, in the optimization of the intake side of the absorption refrigeration system, only the influences of the supply and return water flow and the temperature of the cooling water on the performance of the absorption chillers are considered. However, the river water temperature and intake water flow are also related to the performance of gasfired generators. Integrating the performance of gas-fired generators with the water intake side of the absorption refrigeration system studied in this work and considering the relationship between gas-fired generators and absorption chillers can be the future research direction in establishing the model and optimizing the water intake side of the new integrated system.

\section{Acknowledgements}

The study was supported by the Science and Technology Research Program of Chongqing Municipal Education Commission of China (Grant No. KJQN201804003).

This is an Open Access article distributed under the terms of the Creative Commons Attribution License

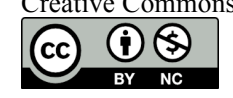

\section{References}

1. Zheng, J.J., "Study of the Off-design Performance of Absorption Chiller in Distributed Energy System". Master thesis of Chinese Academy of Sciences, China, 2012, pp.5-14.

2. Broad Air Conditioner Co., Ltd., "Handbook for selection and design of Broad non-electric air conditioner" [EB/OL]. Retrieved from https://wenku.baidu.com/view/43a301484028915f814dc221.html, 2015-07-04/2017-09-28.

3. American tring air conditioning Co., Ltd., "CVHE_CVHG_CDHG

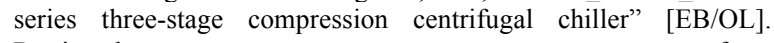
Retrieved from http://wenku.baidu.com/link?url=e3V21f97mTdCS31MahWUZJffk A1L45jGF6LdBP5kKXzwDX33ppNHcDNX6NcQ12uhXDJjvCLzc s5K3fqJL5g2M4y9mOwqkP0Fo2MT7kO-G3u, 2011-10-10/201709-28.

4. Xu, G., Dai, Y., Tou, K., Tso. C., "Theoretical analysis and optimization of a double-effect series-flow-type absorption chiller". Applied Thermal Engineering, 16(12), 1996, pp.975-987.

5. Arosio, S., Guilizzoni, M., Pravettoni., F., "A model for microtrigeneration systems based on linear optimization and the Italian tariff policy". Applied Thermal Engineering, 31(14-15), 2011, pp.2292-2300.

6. Sun, Y.L., "Performance Analysis of Solar Absorption Refrigeration System Driven by the CPC as the Heat Source". Master thesis of Shandong University, China, 2012.pp.34-44.
7. Khalid A. Joudi, Ali H. Lafta. "Simulation of a simple absorption refrigeration system". Energy Conversion and Management, 42(2), 2001, pp.1575-1605.

8. Sun, J., Fu, L., Zhang, S., Hou, W., "A mathematical model with experiments of single effect heat absorption pump using LiarHZO”. Applied Thermal Engineering, 30(17), 2010, pp.2753-2762.

9. Arun, M.B., Maiya, M.P., Murthy, S.S., "Performance comparison of double effect parallel flow and series flow water-lithium bromide absorption systems". Applied Thermal Engineering, 21(12), 2001, pp.1273-1279.

10. Kaushik, S.C., Arora, A., "Energy and exergy analysis of single effect and series flow double effect water-lithium bromide absorption refrigeration systems", International Journal of Refrigeration, 32(6), 2009, pp.1247-1258.

11. Kilic, M., Kaynakli, O., "Theoretical study on the effect of operating conditions on performance of absorption refrigeration system". Energy Conversion and Management, 48(2), 2007, pp.599-607.

12. Park, C.W., Jeong, J.H., Kang, Y.T., "Energy consumption characteristics of an absorption chiller during the partial load operation". International Journal of Refrigeration, 27(8), 2004, pp.948-954.

13. Manzela, A.A., Hanriot, S.M., Luben, C.G., Sodre, J.R., "Using engine exhaust gas as energy source for an absorption refrigeration system". Applied Energy, 87(4), 2010, pp.1141-1148. 
Zhang Wei, Lu Jun, Shan Honghao, Fu Daoyou and Huang Feng/

Journal of Engineering Science and Technology Review 11 (6) (2018) 125 - 137

14. Zheng, J.J., Guo, P., Sui, J., et al., "Off-Design Performance of an exhaust-fired absorption refrigerator". Journal of Engineering Thermophysics, 33 (8), 2012, pp.1275-1278.

15. Zhang, J., "The Study of Developing Modeling Library of Absorption Chiller Systems Based On Modelica/Dymola”. Master thesis of Zhejiang University of Technology, China, 2013, pp.53-60.

16. Zhang, X.H., Wu, J.Q., "Research on Behavior and Modeling of Absorption Chiller". Journal of Mechanical Engineering, 46(2), 2010, pp.119-125.

17. Yang, C., Yang, Z.L., Cai, R.X., “A Modified DOE-2 Model for Typical Performance of Absorption Chillers and its Application". Journal of Refrigeration, 28(6), 2007, pp.51-56.

18. Li, W.Z., Quan, S.L., Chen, G.J., et al., "Optimization design of lithium-bromide absorption refrigerator". Journal of Dalian University of Technology, 50(1), 2010, pp.42-45.

19. Yang, Q.R., Jiang, P.P., Wang, C.P., "Circulating Mode of Solar Absorption Refrigeration with Auxiliary Energy". Gas and Heat, 26(11), 2006, pp.64-67.

20. Liu, D.P., "Simulation on Direct-fired Absorption Refrigerator in Air Conditioning System". Master thesis of Harbin Engineering University, China, 2006, pp.56-67.

21. Yang, Y.Y., "Performance Study of Solar LiBr Absorption Chiller and its Application". Master thesis of Dalian University of Technology, China, 2013, pp.47-60.

22. Zhang, L., "Study on Suction Type and Optimal Operation of Pumping Station Near River with Broad Water Level Variation in the River". Master thesis of Wuhan University, China, 2004, pp.4555
23. Ji, X., "The Operation Scheduling Strategy of Raw Water Pumping Station Based on Dynamic Programming". Master thesis of Tongji University, China, 2007, pp.38-61.

24. Ding, X.L., "Research on Optimized Operating of Water Intake and Water Feed Equipment in Waterworks". Master thesis of Harbin University of Science and Technology, 2008. pp.35-44.

25. Gao, W., "Research on saving energy and applicability in Surface Water Source Heat Pump System”. Master thesis of Chongqing University, China, 2010, pp.45-55.

26. Zhang, Z.J., "Study on Water Supply Pumping Station Optimization and its Application". Master thesis of Chongqing University, China, 2012, pp.54-59.

27. Yang, W., "Research on the Application of Conversion Technology in Water Intake Pumping Station with Water Level Variation", Master thesis of Harbin Institute of Technology, 2012, pp.48-54.

28. Li, M., "The Research of Water Temperature Generation Method and its Application for River Water Source Heat Pump". Master thesis of Chongqing University, China, 2014, pp.77-90.

29. Liao, X.Z., "Characteristic Research and Optimum Type Selection of the Water Intake System of River Water Source Heat Pump System". Master thesis of Chongqing University, China, 2014, pp. $52-60$.

30. Tian, H.F., "Research of the relationship between river water temperature and air temperature in river water source heat pump design". Journal of Thermal Science and Technology, 13(2), 2014, pp.150-156. 